\title{
全球气候变化影响下中亚水土资源与农业发展 多元匹配特征研究
}

\author{
何理 $^{1,2^{*}}$, 王喻宣 ${ }^{1,2}$, 尹方平 ${ }^{1,2}$, 管延龙 ${ }^{3}$ \\ 1. 天津大学水利工程仿真与安全国家重点实验室, 天津 300350 ; \\ 2. 天津大学建筑工程学院, 天津 300350 ; \\ 3. 华北电力大学可再生能源学院, 北京 102206 \\ *通讯作者, E-mail: helix111@tju.edu.cn
}

收稿日期：2019-08-13; 收修改稿日期：2019-12-22; 接受日期：2020-01-14; 网络版发表日期：2020-07-23

中国科学院战略性先导科技专项项目(编号: XDA20040302)和国家自然科学基金创新团队项目(批准号: 51621092)资助

\begin{abstract}
摘要 随着气候变化和社会经济的发展, 科学揭示中亚水土资源和农业发展之间的匹配程度, 对中亚可持续发展 具有重要的战略意义. 文章在综合分析中亚五国2002 2015年关于可利用降雨量、谷物播种面积与谷物产量的基 础上, 首先研究中亚水资源、土地资源和农业发展三要素间的二元匹配特性; 然后提出基于重心公式的多元匹配 评估模型和分级标准，用于分析三要素的多元时空匹配特征; 最后探讨未来气候变化(升温1.5、2 $2^{\circ} \mathrm{C}$ )对多元时空 匹配特征的影响. 研究表明: 中亚的资源与发展间二元匹配度大部分处于中等匹配水平以上，两两要素之间协同 较好; 位于下游的土库曼斯坦和鸟兹别克斯坦的农业发展潜力尚未充分挖掘, 而上游的吉尔吉斯斯坦和塔吉克斯 坦以及下游的哈萨克斯坦水土资源开发利用程度较低, 农业发展受到了限制; 温度上升在时间尺度上会降低多元 匹配度水平, 在空间尺度上对多元匹配度的影响很小, 其中对上游国家空间匹配度的影响相对较大, 需要更加合 理分配水资源以充分提高农业发展潜力。
\end{abstract}

关键词中亚, 水土资源, 农业发展, 匹配度, 气候变化

\section{1 引言}

作为人类社会发展进程中必不可少的资源，水土 资源和农业发展的协同关系对一个国家或区域可持续 发展具有至关重要的作用. 随着社会经济的迅猛发展, 人类对水土资源的需求加大，水土资源逐渐成为制约 农业发展的重要因素; 继而，资源与发展间的现状可 能影响中亚地区区域可持续发展。从地理位置考虑,
中亚地处亚欧大陆腹地, 为东进西出和南下北上的必 经之地, 地理位置优越, 但中亚气候干燥, 温度变化剧 烈及降雨量较少，大部分地区属于温带大陆性干旱气 候(杨恕和田宝, 2002; Lioubimtseva等, 2005; Miao等, 2012). 中亚地区狭义上包括哈萨克斯坦(KAZ)、塔吉

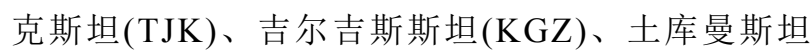
(TKM) 和乌兹别克斯坦(UZB)(Cowan, 2007), 其中哈萨 克斯坦、土库曼斯坦、乌兹别克斯坦为下游国家，吉

中文引用格式: 何理, 王喻宣, 尹方平, 管延龙. 2020. 全球气候变化影响下中亚水土资源与农业发展多元匹配特征研究. 中国科学: 地球科学, 50: 1268-1279, doi: 10.1360/SSTe-2019-0178

英文引用格式: He L, Wang Y, Yin F, Guan Y. 2020. The multivariate matching properties among water and soil resources and agricultural development in Central Asia under global climate change (in Chinese). Scientia Sinica Terrae, 50: 1268-1279, doi: 10.1360/SSTe-2019-0178 
尔吉斯斯坦和塔吉克斯坦为上游国家.

从水资源角度看, 中亚作为农业用水大户, 农业用 水量占总用水量的 $90 \%$ 以上，但水资源在空间上存在 量不足、分布不平衡、跨界水资源冲突严重、低效高 耗等各类水问题, 使供需矛盾加剧, 成为农业发展的限 制性因素(Siegfried等, 2012; Karthe等, 2015; 姚海娇和 周宏飞, 2014; 杨胜天等, 2017). 据联合国粮农组织数 据库(FAO)对中亚水资源数据统计，2016年除哈萨克 斯坦外，其余国家农业用水量占总用水量的比例均在 $90 \%$ 以上; 上游国家地表水资源为中亚地区的 $2 / 3$ 以上. 且目前，中亚地区每年人均水资源量为 $2800 \mathrm{~m}^{3}$ ，低于 $3000 \mathrm{~m}^{3} /$ 人, 总体上属于轻度缺水地区. 另外统计 2002 2015年多年降雨数据可看出上游国家降雨资源 整体上高于下游国家(图1a)，说明降雨资源空间分布 很不均衡. 从土地利用角度看, 中亚地区地广人稀, 人 均耕地面积相当于中国的 6倍, 且土地类型多样, 为农 业发展提供良好的基础, 但其中近一半地区为荒漠、 半荒漠状态，且部分土地存在盐碱化、土壤侵蚀、土 地退化等问题(Small等，2001; Bezborodov等，2010; Devkota等，2015; Hamidov等，2016; Kulmatov等, 2018). 据FAO对中亚土地利用类型数据统计，2016年 中亚耕地面积为 $3771 \times 10^{4} \mathrm{hm}^{2}$, 占农业用地面积的 $12.88 \%$ ，其中下游国家耕地面积占据中亚地区耕地面 积的 $95 \%$ 以上. 另外统计2002 2015年各国多年谷物播 种面积可知, 哈萨克斯坦谷物播种面积占中亚谷物播 种面积 $80 \%$ 左右(图 $1 \mathrm{~b}$ ), 为中亚地区最大粮食生产国, 农业发展潜力大.

而对于与水土资源紧密联系的农业发展状况，苏 联解体后，由于水利及农业基础设施老化、种植技术 水平低、采用低效粗放型经营策略等原因, 致使农业 发展呈现缓慢增长或停滞不前的现象, 又引发了生态 环境问题(O'Hara，2000; Micklin, 2007; Kienzler等, 2012)。针对当前农业发展缓慢及水土资源短缺现状, 中亚各国急需寻找一种手段来确保粮食安全. 依据 FAO有关规定，“粮食”主要是指小麦、稻谷等谷物 (Zhang等，2018), 而根据有关文献研究(Micklin, 2007), 中亚过去将更多灌溉面积作物转化为低水分作 物(如谷物代替棉花)，其中从1990 1998年，棉花种植 面积的百分比从 $45 \%$ 下降为 $25 \%$ ，而冬小麦种植面积 占比上升到 $28 \%$, 说明谷物发展空间较大. 且通过中亚 2002 2015年谷物产量年均分布图看(图1c), 中亚地区
农业仍有较高的发展潜力和前景. 因此, 本文将谷物产 量作为衡量农业发展水平的指标.

随着全球气候变暖(Sorg等, 2012; 胡婷等, 2017; Zhou等, 2018)与社会经济发展, 人类对水土资源的需 求逐渐加大, 水土资源间的矛盾也随之增大, 因而用来 衡量和表征水资源、土地资源和经济发展状况等协调 程度的重要指标-匹配度, 已成为一个国家或区域可持 续发展的一种重要研究方法. 目前, 国内外学者针对中 亚地区水土资源及其匹配现状已展开了众多研究, 如 Qadir等(2009)通过对咸海流域水土资源的定量研究, 发现灌溉和盐度引起的水土资源退化和不匹配问题, 严重威胁农业的可持续发展. 邓铭江等(2010)通过对 中亚水资源量及分布特点与经济社会发展的定性研 究, 发现中亚水资源在空间分布上严重不均衡且存在 低效粗放的管理和运用问题．郝林钢等(2018)运用基 于数列的匹配度计算方法, 研究中亚地区水资源利用 与经济社会发展的时空匹配度，发现其在时间尺度上 呈先上升后下降的趋势, 在空间尺度上匹配程度为上 游国家大于下游国家. 吉力力.阿不都外力等(2009)通 过生态安全评估PSR模型对中亚区域多年水土资源变 化情况进行对比分析, 发现除哈萨克斯坦外的其余国 家人均水资源量逐渐降低, 除土库曼斯坦外的其余国 家人均耕地面积逐年减少，中亚地区水土资源量短缺. 姚海娇等(2013)运用基尼系数法和单位面积耕地所拥 有的水资源量法，研究中亚水土资源在区域和国家尺 度上空间匹配关系, 发现中亚整体匹配状况良好, 但 各国之间差异较大，即下游国家较上游国家匹配状况 较差. 但对于农业发展的水平, 决定因素不仅包括水 资源供给量，土地资源供应量，以及水土资源的在时 间和空间尺度上的匹配水平，还取决于三者之间的协 同关系.

总的来说, 目前国内外主要从市域(刘彦随等, 2006)、省域(黄克威等, 2015)、流域(李志等, 2010)、 国家(许长新等, 2016; 陈紫璇等, 2019)等不同层次对 水土资源之间的二元匹配程度开展系列研究, 但均没 有深入研究水土资源与农业发展水平之间的多元匹配 水平和演变特征. 一般来说, 作为制约农业发展最核心 的要素, 水和土地两种资源间的匹配度越高, 越有利于 农业发展, 反之则不利于农业发展. 但是, 水土资源匹 配度越高, 并不能说明农业发展水平越高. 因此, 本文 拟提出一种能反映资源与发展之间的多元匹配度评估 

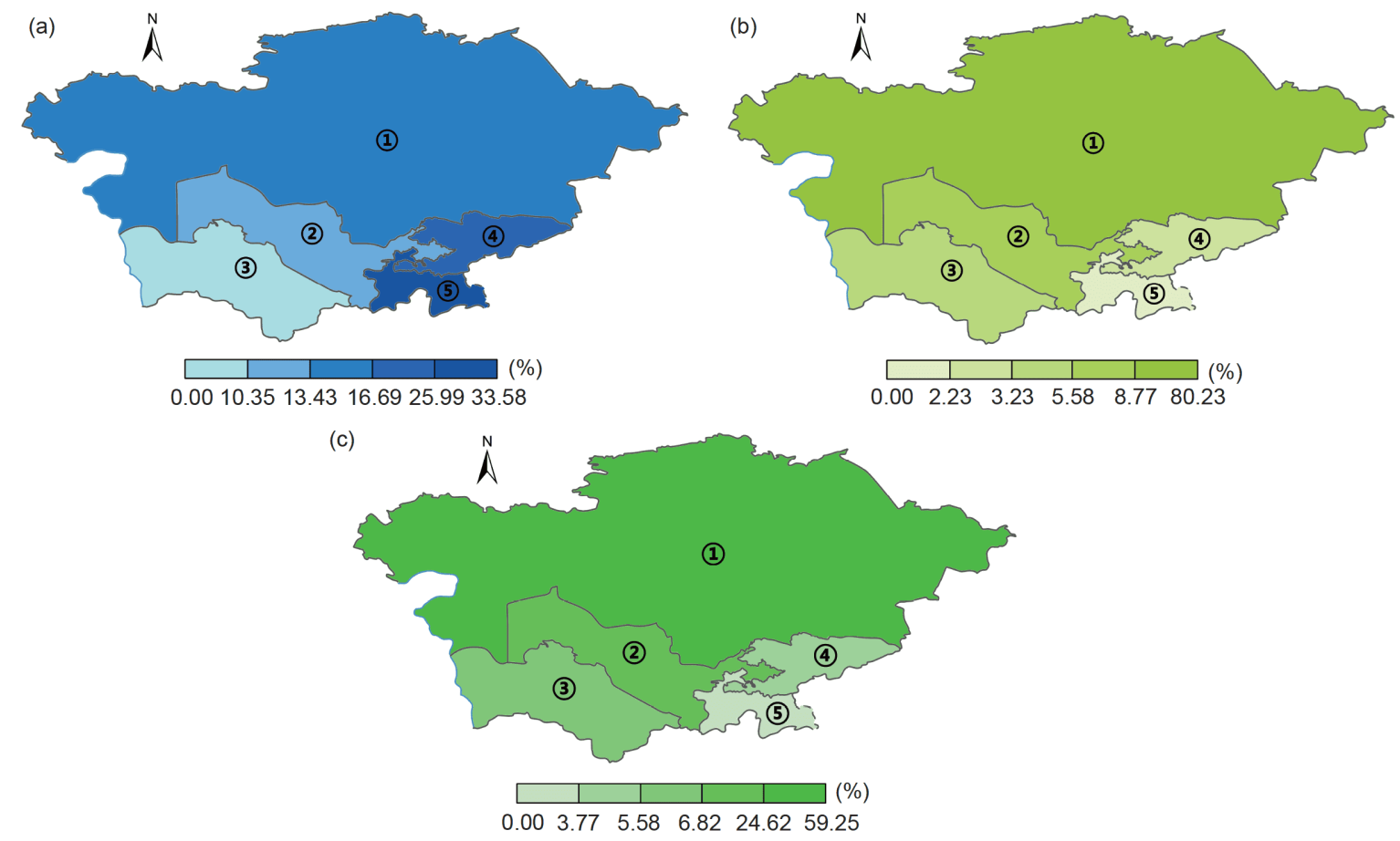

图 $1 \quad 2002 ~ 2015$ 年中亚水、土资源和农业发展水平分布示意图

(a) 年均降雨量; (b) 年均谷物播种面积; (c) 年均谷物产量. (1) 哈萨克斯坦; (2) 乌兹别克斯坦; (3) 土库曼斯坦; (4) 吉尔吉斯斯坦; (5) 塔吉克斯坦

新模型，以评估水、土资源和农业发展三者之间在时 空尺度的匹配水平. 通常来说, 匹配度越高, 则说明农 业发展水平与水土资源禀赋间协调关系越好，农业生 产对水土资源潜力的挖掘程度越大，但农业发展的潜 力更小，反之，则说明农业发展与水土资源分配越不 合理，发展水平与资源开发利用越不协调，但农业发 展潜力更大. 因此，本文提出的指标既要能够评估农 业发展与水土资源间的匹配特征，揭示农业发展与水 土资源间的协同关系，又能间接反映水土资源制约下 的农业发展潜力.

基于以上考虑，本文拟在综合分析中亚五国 2002 2015年关于可利用降雨量、谷物播种面积与谷 物产量的基础上，首先研究中亚水资源、土地资源与 农业发展三要素间的二元匹配特性；然后构建基于重 心公式的多元匹配评估模型和提出多元匹配分级标 准, 用于分析三要素的多元时空匹配特征; 最后基于全 球气候模式比较计划(CMIP5)获取的气候变化模式数 据, 探讨未来气候变化 (升温 $1.5^{\circ} \mathrm{C} 、 2^{\circ} \mathrm{C}$ ) 对多元时空匹 配特征的影响，为制定水土资源开发利用与农业发展 的协同管理措施和政策，为应对全球气候变化，提供
新的科学依据.

\section{2 数据来源及研究方法}

\section{1 数据来源}

本文采用的数据主要由网站下载数据和计算所得 数据两部分组成, 其中, 中亚各国农业耕地面积数据和 农作物产量数据均来自联合国粮农组织数据库(http:// www.fao.org/faostat/en/\#data), 中亚地区逐月降雨量历 史数据和月平均温度历史数据均来自世界银行气候变 化知识门户网站(https://climateknowledge portal.worldbank.org/). 关于全球气候变化下未来的降雨数据, 则 基于全球气候模式比较计划(CMIP5)的结果，选择 $\mathrm{RCP} 4.5$ 情景下升温 1.5 和 $2{ }^{\circ} \mathrm{C}$ 时中亚地区近地面数据 图，利用ArcGIS、MATLAB软件提取，得到近地面逐 月月平均气温和降雨量数据. 而另一部分计算所得数 据则由中亚各国历史或升温 1.5 与 $2^{\circ} \mathrm{C}$ 降雨量和气温数 据计算得到相应蒸发量数据和可利用降雨量数据. 但 由于中亚位于干旱半干旱地区, 降雨量少, 蒸发大, 地 下水埋藏较深, 因此本文未考虑地下水供给. 根据相关 
文献，由施雅风(1995)研究成果可知, 可利用地表水资 源量相关因子之间的关系，可以由水量平衡方程式(1) 来确定:

$B=P_{0}-R-E-W$,

式中, $B$ 为水量平衡因子, $P_{0}$ 为地表平均降雨量, $E$ 为地 表平均蒸发量, $R$ 为河流流量, $W$ 为土壤蓄水量. 当区域 处于稳定状态时, 多年水量平衡 $B$ 为零, 而地表蒸发的 水分难以利用, 因此降雨量减去地表蒸发量(即河流流 量和地表蓄水量之和)为可以利用的降雨量, 本文称其 为可利用降水量 $P$, 可表示为

$P=R+W=P_{0}-E$,

其中地表平均蒸发量 $E$ 可由高桥浩一郎(1979)公式(3) 计算得到:

$$
E=\frac{3100 P_{0}}{3100+1.8 P_{0}^{2} \exp \left(-\frac{34.4 T}{235.0+T}\right)} .
$$

式中, $T$ 为地面平均温度.

\section{2 资源与发展多元匹配评估模型}

本文首先采用传统的基于数列匹配度计算方法 (左其亭等, 2014; 郝林钢等, 2018), 对变量之间的匹配 程度进行定量分析. 现研究中亚水资源、土地资源和 农业发展三要素间的二元时空匹配特性，计算方法具 体如下: 将可利用降雨量、谷物播种面积和谷物产量 两两变量 $X$ 和 $Y$ 按照时间分为 $T$ 个时段, 数对 $\left(x_{t}, y_{t}\right)$ 分别 为第 $t$ 个时段 $X$ 和 $Y$ 的值，则时间尺度上的匹配度 $A_{t}$ 可按 下式(4)计算:

$A_{t}=1-\frac{\left|r_{t}-s_{t}\right|}{\max \left(r_{i}, s_{i}\right)-\min \left(r_{i}, s_{i}\right)},(i=1,2,3, \ldots, T)$,

其中, $r_{t}=\frac{x_{t}}{\sum_{i=1}^{T} x_{i}}, s_{t}=\frac{y_{t}}{\sum_{i=1}^{T} y_{i}}$.

类似的将研究区域在空间上分为 $K$ 个单元，分析 变量 $X$ 和 $Y$ 的匹配度, 数对 $\left(x_{k}, y_{k}\right)$ 为第 $k$ 个子单元变量 $X$ 和 $Y$ 的值, 则空间尺度上的匹配度 $A_{k}$ 可按下式(5)计算:

$$
A_{k}=1-\frac{\left|r_{k}-s_{k}\right|}{\max \left(r_{j}, s_{j}\right)-\min \left(r_{j}, s_{j}\right)},(j=1,2,3, \ldots ., K),
$$

其中, $r_{k}=\frac{x_{k}}{\sum_{j=1}^{K} x_{j}}, s_{k}=\frac{y_{k}}{\sum_{j=1}^{K} y_{j}}$.

此外, 由于重心模型在探索要素演变和协同关系
方面具有独特优势，既被广泛应用于研究单一要素空 间格局演化轨迹, 如土地利用重心(王海军等, 2018)、 降水重心(赵志龙等，2018)等，又被应用于考察2个要 素同步性变化方面(徐建华和岳文泽，2001; 荣慧芳和 方斌, 2017). 因此, 本文为了对深入研究中亚地区多元 匹配特性, 利用重心公式的思维, 提出基于重心公式的 多元匹配评估模型，探讨三要素资源与发展多元时空 匹配特性. 多元匹配评估模型具体步骤如下, 将变量 可利用降雨量 $P$ 、谷物播种面积 $S$ 和谷物产量 $A$ 按照时 间(区域)分为 $T(K)$ 个时段(单元), 数对 $\left(P_{t(k)}, S_{t(k)}, a_{t(k)}\right)$ 分 别为变量可利用降雨量 $P$ 、谷物播种面积 $S$ 和谷物产 量 $A$ 在第 $t(k)$ 个时段(单元)的值, 按照下式(6)计算出每 个时段(单元)所占的比例 $r_{t(k)} 、 v_{t(k)} 、 w_{t(k)}$ :

$$
\begin{aligned}
& r_{t(k)}=\frac{p_{t(k)}}{\sum_{i=1}^{T(K)} p_{i}}, v_{t(k)}=\frac{s_{t(k)}}{\sum_{i=1}^{T(K)} s_{i}}, \\
& w_{t(k)}=\frac{a_{t(k)}}{\sum_{i=1}^{T(K)} a_{i}},(i=1,2,3, \ldots, T(K)) .
\end{aligned}
$$

利用max-min标准化法对数据进行标准化处理:

$$
\begin{aligned}
\alpha_{t(k)} & =\frac{\left|r_{t(k)}-\min \left(r_{i}\right)\right|}{\max \left(r_{i}\right)-\min \left(r_{i}\right)}(i=1,2,3, \ldots, T(K)), \\
\beta_{t(k)} & =\frac{\left|v_{t(k)}-\min \left(v_{i}\right)\right|}{\max \left(v_{i}\right)-\min \left(v_{i}\right)}(i=1,2,3, \ldots,(K)), \\
\gamma_{t(k)} & =\frac{\left|w_{t(k)}-\min \left(w_{i}\right)\right|}{\max \left(w_{i}\right)-\min \left(w_{i}\right)}(i=1,2,3, \ldots,(K)) .
\end{aligned}
$$

图2所示 $\Delta \mathrm{PSA}$ 是边长为 1 的正三角形, 三个顶点的 坐标分别为 $P\left(-\frac{1}{2},-\frac{\sqrt{3}}{6}\right) 、 S\left(0, \frac{\sqrt{3}}{3}\right) 、 A\left(\frac{1}{2},-\frac{\sqrt{3}}{6}\right)$, 其重 心为原点 $O$, 将其标准化后的值 $\alpha_{t(k)} 、 \beta_{t(k)} 、 \gamma_{t(k)}$ 作为 比例, 分别在各自的对应边上确定每组数据所在位 置 $P^{\prime}\left(x_{1}, y_{1}\right) 、 S^{\prime}\left(x_{2}, y_{2}\right) 、 A^{\prime}\left(x_{3}, y_{3}\right)$, 其中:

$$
\begin{aligned}
& x_{1}=-\frac{1}{2}+\alpha_{t(k)} \times \cos \frac{\pi}{3}, \\
& y_{1}=-\frac{\sqrt{3}}{6}+\alpha_{t(k)} \times \sin \frac{\pi}{3}, \\
& x_{2}=\beta_{t(k)} \times \sin \frac{\pi}{6}, \\
& y_{2}=\frac{\sqrt{3}}{3}-\beta_{t(k)} \times \cos \frac{\pi}{6}, \\
& x_{3}=\frac{1}{2}-\gamma_{t(k)}, y_{3}=-\frac{\sqrt{3}}{6} .
\end{aligned}
$$

构成新的三角形 $\Delta P^{\prime} S^{\prime} A^{\prime}$, 其重心为 $O^{\prime}\left(x_{0}, y_{0}\right)$, 计 


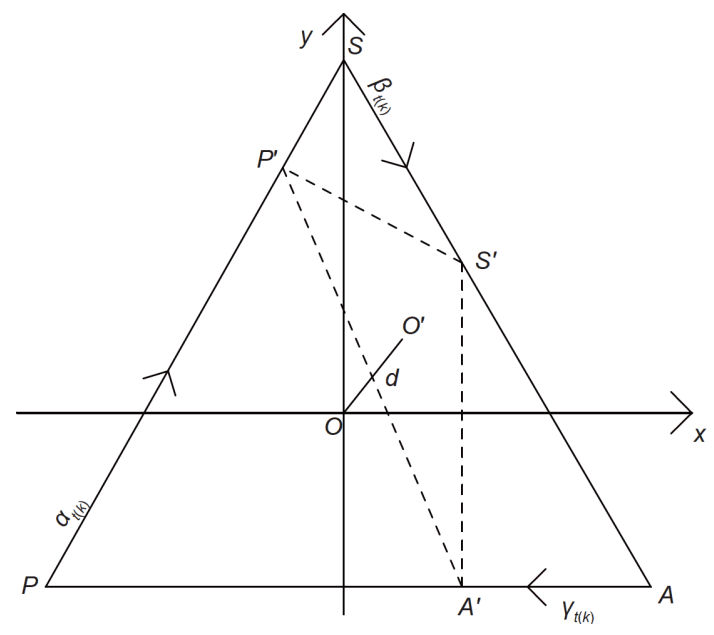

图 2 多元匹配度计算模型

$P 、 S 、 A$ 分别为可利用降雨量、谷物播种面积及谷物产量; $O$ 为重 心原点、 $O^{\prime}$ 为偏移重心, $d$ 为偏移程度; $\alpha_{t(k)} 、 \beta_{t(k)} 、 \gamma_{t(k)}$ 为每个时段 (单元)变量标准化后的值; $P^{\prime} 、 S^{\prime} 、 A^{\prime}$ 分别为每组变量标准化在对应 边确立的位置

算 $O$ 和 $O^{\prime}$ 之间的偏离程度 $d$, 其偏离程度 $d$ 越大则表示 资源与发展在时间和空间尺度上越不匹配，具体计算 公式如下:

$x_{0}=\frac{x_{1}+x_{2}+x_{3}}{3}, y_{0}=\frac{y_{1}+y_{2}+y_{3}}{3}$,

$d=\sqrt{x_{0}^{2}+y_{0}^{2}},\left(0 \leq d \leq \frac{1}{3}\right)$.

并根据公式(10)进一步求出中亚研究区域的水、土资 源和农业发展标准化多元匹配度 $A_{3 d}$ ，以表示多个要素 在时空上的匹配程度:

$A_{3 d}=1-3 d,\left(0 \leq A_{3 d} \leq 1\right)$.

最后，参考联合国有关组织对基尼系数的划分标准与 相关文献(姚海娇等，2013), 确定二元匹配度分级标 准，后在二元匹配度分级标准的基础上，利用重心公 式思维，提出多元匹配度分级标准(表1), 评估资源-发 展之间的协同关系.

\section{3 中亚水土资源与农业发展匹配特征分析}

\section{1 二元时间匹配特征}

利用中亚五国可利用降雨量、谷物产量、谷物播 种面积等数据, 采用传统的基于数列匹配度计算方法, 在时间尺度上，从二元匹配角度考虑，计算中亚
2002 2015年可利用降雨量、谷物播种面积与谷物产 量三要素间的时间匹配程度, 利用表1分析两者的时间 匹配特征，研究两者间的协同关系，制定针对性措施， 并作为研究多元匹配特征的基础.

(1) 可利用降雨量-谷物产量匹配特征(图3a). 从整 体上看，2002 2015年中亚整体匹配度大部分处于 0.6 以上，说明中亚水资源和农业发展匹配状况相对合理. 然而仍有不少数据处于 0.5 以下匹配极差水平, 如 2003 年塔吉克斯坦匹配度为 0.2 , 主要为可利用降雨量较年 均降雨量增加了 $45 \%$, 谷物产量变化较小, 说明该国没 有有效利用降雨资源, 使得大量水资源流出该国, 造成 其匹配度极差. 2002、2003年乌兹别克斯坦由于机械 设备老化，基础设施不健全，使谷物产量增长缓慢或 停滞不前, 造成匹配水平极差, 但后期由于设施逐渐 改进, 匹配度逐渐上升. 2006年除土库曼斯坦外, 皆处 于匹配较好水平，原因为土库曼斯坦谷物产量较2005 年增加了 $15 \%$, 使匹配度突降. 吉尔吉斯斯坦和塔吉克 斯坦同为上游国家, 降雨资源丰富, 耕地少, 匹配度变 化趋势大致相同.

(2) 可利用降雨量-谷物播种面积匹配特征(图3b). 从整体上看, 各国匹配度变化趋势大致相同, 除个别数 据外均高于 0.6 , 说明中亚地区水土资源匹配度处于中 等匹配水平. 其中2002 2004年吉尔吉斯斯坦、塔吉克 斯坦、乌兹别克斯坦匹配度在 $0.3 \sim 0.9$ 浮动, 波动较大, 但变化趋势大致相同. 据FAO统计分析, 三国表现为可 利用降雨量增多, 但由于谷物播种面积仅在小范围内 波动，造成匹配度变化大，可通过调配使水土资源匹 配均衡. 2014年后, 中亚匹配度呈现下降趋势, 主要原 因为哈萨克斯坦、塔吉克斯坦和吉尔吉斯斯坦可利用 降雨量突增, 土库曼斯坦和乌兹别克斯坦可利用降雨 量减少, 无法与谷物播种面积的需求相协调, 造成两 者不匹配. 在这两者匹配度中，五国播种面积变化很 小, 说明五国匹配度主要受可利用降雨量影响, 主要 解决水资源调配问题.

(3) 谷物产量-谷物播种面积匹配特征(图3c). 从整 体上看, 2002 2015年匹配度大部分处于 0.7 以, 说明 中亚土地资源和农业发展状况匹配水平较好. 但2004 年乌兹别克斯坦、2006年土库曼斯坦、2011年哈萨克 斯坦均位于匹配极差水平, 其原因大致相同, 2004年乌 兹别克斯坦谷物产量减少. 2006年土库曼斯坦和 2011 年哈萨克斯坦谷物产量较年均产量增加 $59 \%$ 、 $80 \%$, 
表 1 资源-发展多元匹配度分级标准 ${ }^{a)}$

\begin{tabular}{|c|c|c|c|c|}
\hline \multicolumn{2}{|c|}{ 资源-发展二元匹配度分级标准 } & \multicolumn{2}{|c|}{ 资源-发展多元匹配度分级标准 } & \multirow{2}{*}{$\begin{array}{c}\text { 谷物产量对二元匹配度的影响* } \\
\text { 很小 }\end{array}$} \\
\hline & & {$[0,0.4)$} & 极差 & \\
\hline & & {$[0.4,0.5)$} & 较差 & 小 \\
\hline \multirow[t]{5}{*}[0,0.5]{} & 极差 & {$[0.5,0.6)$} & 中等 & 较小 \\
\hline & & {$[0.6,0.7)$} & 较好 & 较大 \\
\hline & & {$[0.7,1)$} & 极好 & 大 \\
\hline & & {$[0,0.4)$} & 极差 & 小 \\
\hline & & {$[0.4,0.5)$} & 较差 & 很小 \\
\hline \multirow[t]{5}{*}{$0.5,0.6$} & 较差 & {$[0.5,0.6)$} & 中等 & 小 \\
\hline & & {$[0.6,0.7)$} & 较好 & 较小 \\
\hline & & {$[0.7,1)$} & 极好 & 较大 \\
\hline & & {$[0,0.4)$} & 极差 & 较小 \\
\hline & & {$[0.4,0.5)$} & 较差 & 小 \\
\hline \multirow[t]{5}{*}{$0.6,0.7$} & {$[0.6,0.7)$} & {$[0.5,0.6)$} & 中等 & 很小 \\
\hline & & {$[0.6,0.7)$} & 较好 & 小 \\
\hline & & {$[0.7,1)$} & 极好 & 较小 \\
\hline & & {$[0,0.4)$} & 极差 & 较大 \\
\hline & & {$[0.4,0.5)$} & 较差 & 较小 \\
\hline \multirow[t]{5}{*}{$0.7,0.8$} & 较好 & {$[0.5,0.6)$} & 中等 & 小 \\
\hline & & {$[0.6,0.7)$} & 较好 & 很小 \\
\hline & & {$[0.7,1)$} & 极好 & 小 \\
\hline & & {$[0,0.4)$} & 极差 & 大 \\
\hline & & {$[0.4,0.5)$} & 较差 & 较大 \\
\hline \multirow[t]{3}{*}{$0.8,1$} & 极好 & {$[0.5,0.6)$} & 中等 & 较小 \\
\hline & & {$[0.6,0.7)$} & 较好 & 小 \\
\hline & & {$[0.7,1)$} & 极好 & 很小 \\
\hline
\end{tabular}

a) *当二元和多元匹配度为同一等级时(如均为“极差匹配”), 谷物产量对二元匹配度的影响等级定义为“很小”; 当二元和多元匹配度相 差一个等级时(如其中一个为“较差匹配”, 另一个为“极差匹配”或“中等匹配”), 谷物产量对二元匹配度的影响等级为“小”; 其余依此类推

而其谷物播种面积在小范围内波动, 使匹配度突降, 土 地资源开发程度较差, 限制了农业发展. 2011 2015年 除哈萨克斯坦外，其他国家匹配度均呈现不断下降趋 势, 主要为谷物产量与谷物播种面积的发展速度不协 调, 没有科学有效的种植技术和土地管理政策.

\section{2 二元空间匹配特征}

利用中亚五国可利用降雨量、谷物产量、谷物播 种面积等数据, 采用传统的数列匹配度计算方法, 在空 间尺度上，从二元匹配角度考虑，计算2002 2015年可 利用降雨量、谷物播种面积与谷物产量三要素间的空 间匹配程度，并利用表1分析两者的空间匹配特征，研
究两者间的协同关系, 制定针对性措施, 并作为多元匹 配特征分析的基础.

(1) 可利用降雨量-谷物产量匹配特征(图4a). 从整 体上看, 中亚各国匹配度处于中等匹配水平以上, 哈萨 克斯坦匹配度在 $0.6 \sim 1$ 波动，幅度较大，其中 2004 、 2006和2010年匹配度较低, 原因为2004年哈萨克斯坦 谷物产量比年均产量降低了 $26.5 \%$, 而可利用降雨量 变化很小；2010年可利用降雨量较均值上升了 $19.5 \%$, 谷物产量下降了 $27.8 \%$. 其他四国匹配度变化幅度较 小, 吉尔吉斯斯坦和土库曼斯坦为极好水平, 明显高 于塔吉克斯坦和乌兹别克斯坦, 其中乌兹别克斯坦匹 配度较低是由于其可利用降雨量仅占中亚五国总量的 

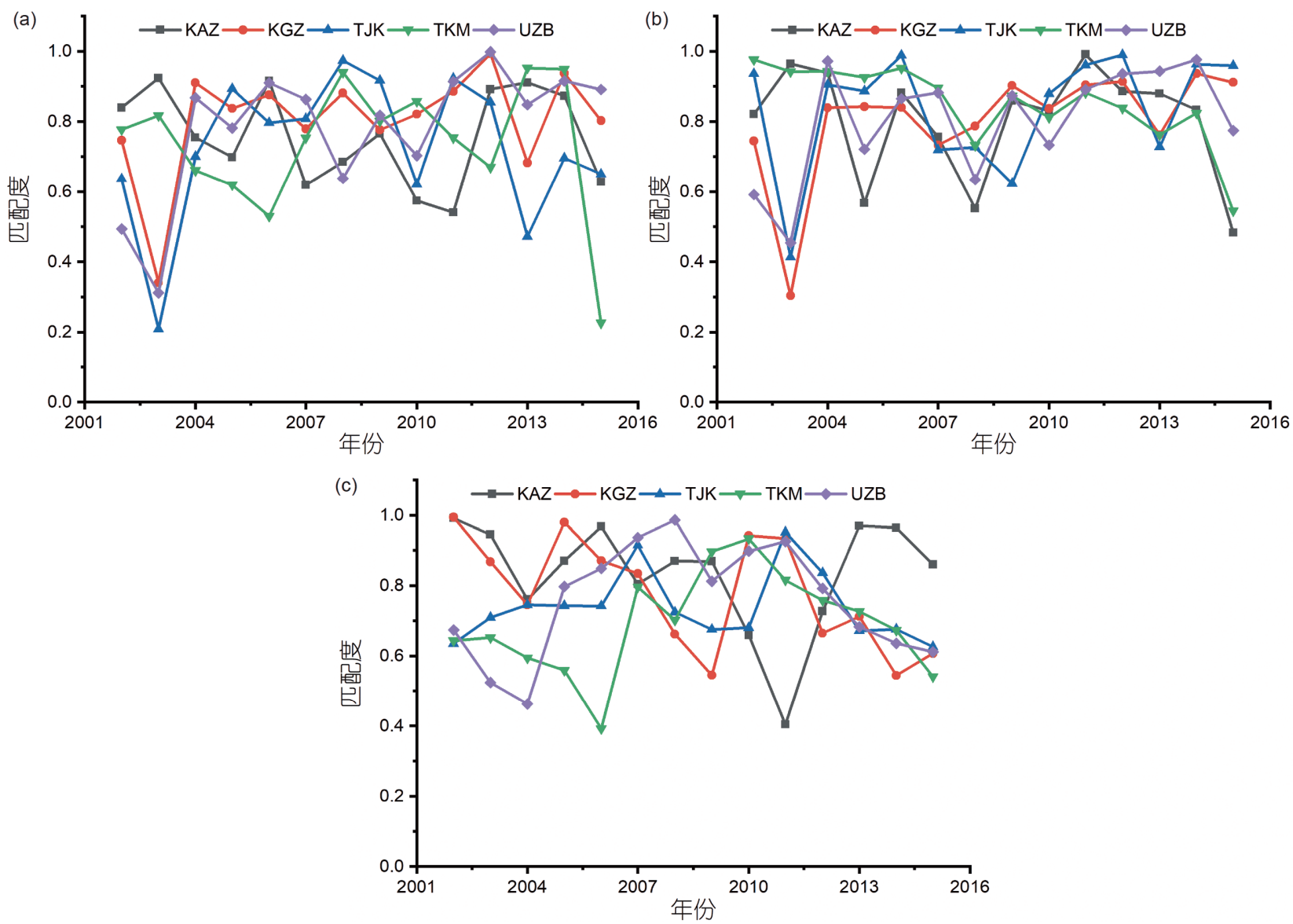

图 3 中亚各国水、土资源与农业发展的二元时间匹配度

(a) 可利用降雨量-谷物产量; (b) 可利用降雨量-谷物播种面积; (c) 谷物产量-谷物播种面积

6 9\%，而其谷物产量却占21 25\%，水资源量少，分布 不均衡.

(2) 可利用降雨量-谷物播种面积匹配特征(图4b). 从整体上看, 中亚地区匹配度处于较好水平, 其中乌兹 别克斯坦和土库曼斯坦匹配度较高且平稳变化，吉尔 吉斯斯坦略低，但仍为极好匹配，说明三国水土资源 空间分布合理. 塔吉克斯坦与哈萨克斯坦匹配度比其 他三国波动较为剧烈，波动特征显示为逐年上升状态. 从2008年开始，中亚整体匹配度皆在 0.8 以上的匹配极 好水平，且各国水土资源在空间上的匹配度逐年上升， 说明中亚各国水土资源在空间上逐渐相协调.

(3) 谷物产量-谷物播种面积匹配特征(图4c). 中亚 谷物产量-谷物播种面积空间匹配度呈现两种明显不 同状态，其中塔吉克斯坦、吉尔吉斯斯坦、土库曼斯 坦匹配度值一直平稳处于 0.9 以上的匹配极好水平，土
库曼斯坦变化幅度略大，且在2006年时有明显上升现 象. 乌兹别克斯坦和哈萨克斯坦匹配度比其他三国较 低且变化幅度较大，其中2010 2012年的匹配度值波 动最大，主要为2011年两国谷物产量分别增加了 $20 \%$ 和降低了 $12 \%$ ，说明存在农业技术落后、土地资源相 对不足等方面的问题.

\section{3 多元时间匹配特征}

利用中亚五国可利用降雨量、预测可利用降雨 量、谷物产量、谷物播种面积等数据，采用基于重心 公式的多元匹配评估模型，在时间尺度上，计算三要 素在历史(2002 2015年)以及升温 $1.5^{\circ} \mathrm{C}(2028 \sim 2041$ 年) 和 $2^{\circ} \mathrm{C}$ (2049 2062年)情形下的多元匹配程度，并利用 表 1 和二元匹配特征分析多元时间匹配特征，制定科 学合理的协同管理措施及政策. 

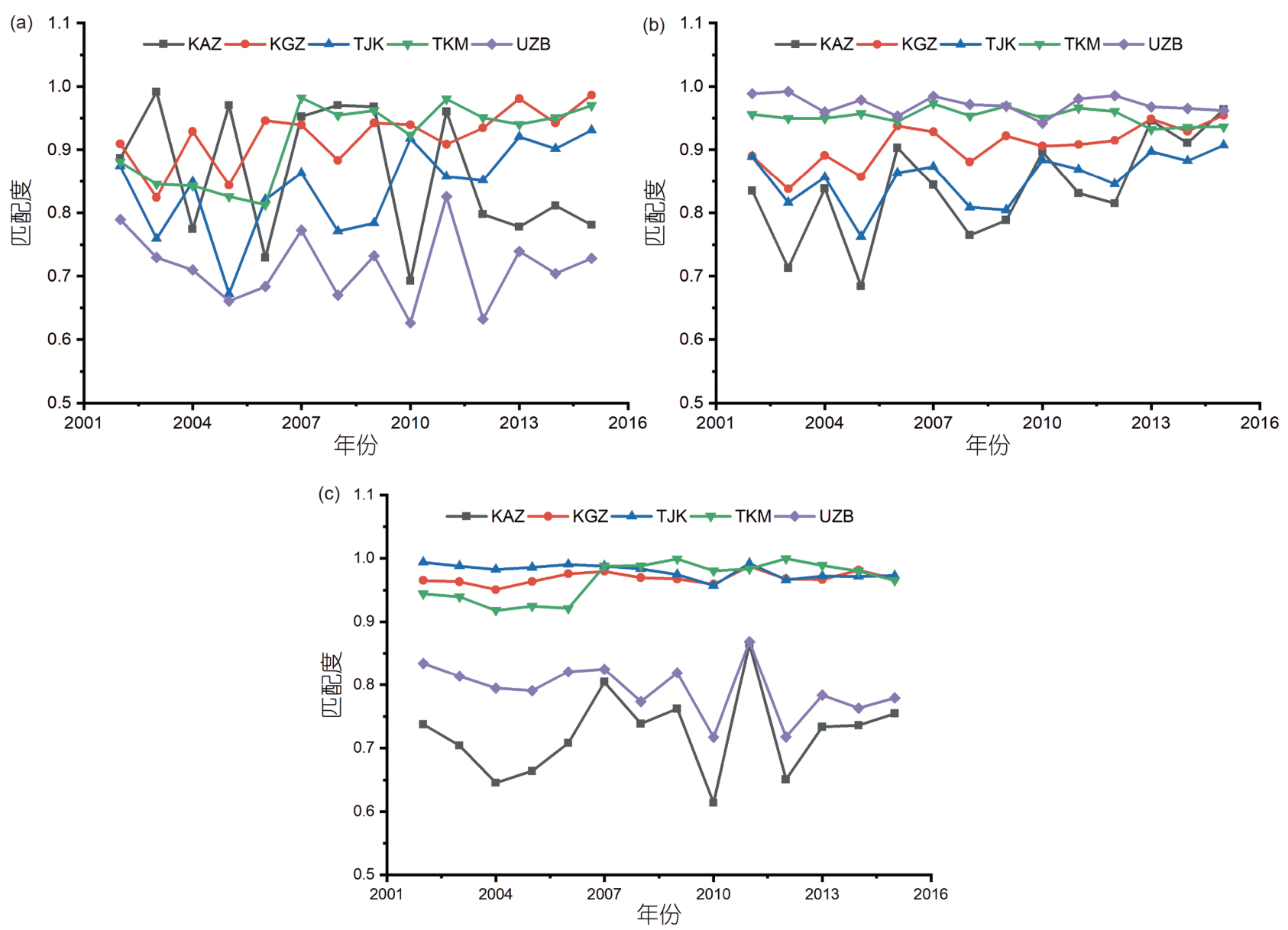

图 4 中亚各国水、土资源与农业发展的二元空间匹配度

(a) 可利用降雨量-谷物产量; (b) 可利用降雨量-谷物播种面积; (c)谷物产量-谷物播种面积

(1) 三要素多元时间匹配特征(图5a). 从二元匹配 度(图3)与多元匹配度(图5a)计算结果出发, 分析中亚 地区多元时间匹配特征, 由于图(3b)新增谷物产量这 一要素, 发现各国多元匹配度下降且波动加剧, 三要 素的协同关系更加复杂. 从整体上分析水土资源二元 匹配度和多元匹配度, 可知土库曼斯坦和乌兹别克斯 坦的多元匹配度受农业发展的影响较大, 农业发展潜 力尚未充分挖掘. 吉尔吉斯斯坦、塔吉克斯坦和哈萨 克斯坦受水土资源影响较大, 且水土资源开发利用程 度较低, 限制了农业的发展. 从国家层面分析, 2010年 哈萨克斯坦、塔吉克斯坦、乌兹别克斯坦匹配度均低 于 0.4, 较 2010 年三国二元匹配度(图3b)下降了 0.4 左右, 说明该国谷物产量对其影响较大, 三者协同关系较差, 应实行科学水土资源管理措施与改进种植技术. 2005、2006年土库曼斯坦为匹配极差水平, 主要为谷
物产量较均值增加了 $80 \% 、 57 \%$ ，农业发展水平较高， 但水土资源配置限制农业发展速度，2011年后则为水 土资源无法满足农业发展的需求，农业发展潜力尚未 充分挖掘, 说明该国应加强水土资源配置效率, 采用 滴灌等技术, 提高水的利用效率.

(2) $\mathrm{RCP}$ 预测雨量下, 升温 1.5 和 $2{ }^{\circ} \mathrm{C}$ 对多元时间匹 配度的影响(图5b、5c). 图5b和5c与历史多元匹配度图 (5a)相比, 由于温度升高, 降雨量随之变化, 中亚各国 整体匹配度波动范围增大 0.3 左右, 变化趋势更加复杂. 从区域整体上看, 温度上升使中亚五国匹配度下降. 从 国家层面分析, 2033年吉尔吉斯斯坦达到了最小值 0.05 , 原因为可利用降雨量较均值增加了 $49 \%$, 而土地 面积和谷物产量仍小幅度变化, 水资源开发利用程度 较低, 三者之间协同关系极差, 使匹配度突降, 未来应 更加重视水资源潜力, 使之高效利用以提高谷物产量. 

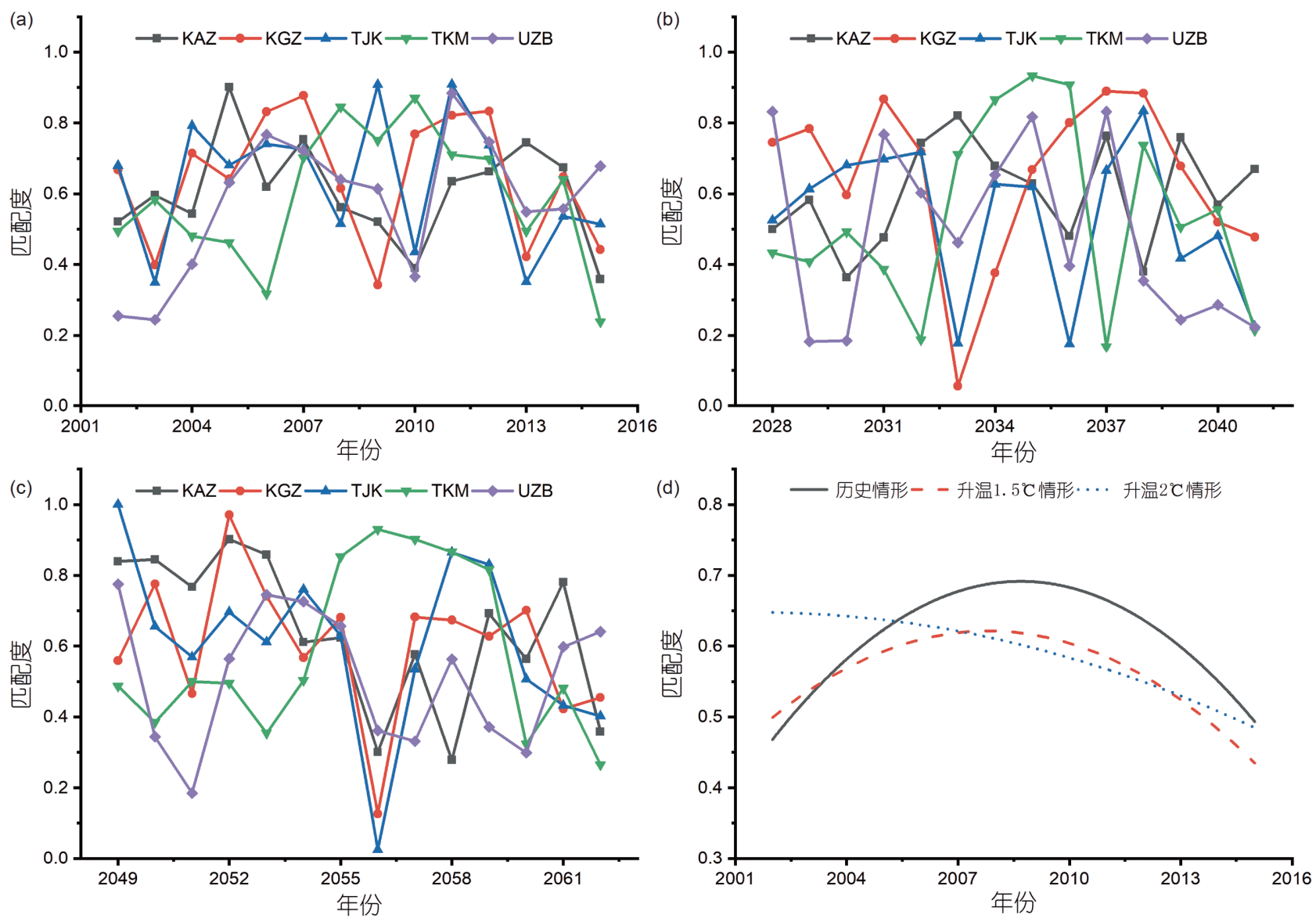

图 5 中亚各国水、土资源与农业发展的多元时间匹配度

(a) 历史情形时间匹配度; (b) 升温 $1.5^{\circ} \mathrm{C}$ 时间匹配度; (c) 升温 $2^{\circ} \mathrm{C}$ 时间匹配度; (d) 中亚历史-温升情形时间匹配趋势对比图, 其中升温 $1.5^{\circ} \mathrm{C}$ 和 $2^{\circ} \mathrm{C}$ 情形与历史情形的年份一一对应, 如2028、2049年与 2002 年对应, 以此类推

2037年除土库曼斯坦外, 都处于中等匹配水平以上, 土 库曼斯坦匹配度突降原因为可利用降雨量较均值突增 1.65 倍, 应加强水资源管理, 提高谷物产量来缓解气候 变化所带来的影响. 在2056年, 除土库曼斯坦外, 其余 国家匹配度均处于匹配极差水平，哈萨克斯坦谷物产 量增加 $23.6 \%$, 其他三国谷物产量降低, 为应对气候变 暖所带来的影响, 应更加重视协调发展, 以提高中亚水 土资源配置及谷物产量.

\section{4 多元空间匹配特征}

利用中亚五国可利用降雨量、预测可利用降雨 量、谷物产量、谷物播种面积等数据，采用基于重心 公式的多元匹配评估模型，在空间尺度上，计算三要 素在历史(2002 2015年)以及升温 $1.5^{\circ} \mathrm{C}$ (2028 2041年) 和 $2^{\circ} \mathrm{C}$ (2049 2062年)情形下的空间匹配程度，并利用
表1及二元空间匹配特征分析多元空间匹配特征，制 定科学合理的协同管理措施及政策.

(1) 三要素多元空间匹配特征(图6a). 从区域整体 分析, 多元匹配(图6a)与二元匹配(图4)相比, 由于新增 一个要素，整体匹配度波动范围增加0.2左右，同时发 现乌兹别克斯坦和土库曼斯坦空间匹配度受农业发展 影响较大，塔吉克斯坦和吉尔吉斯斯坦受水资源影响 较大. 从国家层面上看, 当谷物产量作为新增要素进 行多元匹配度计算时，乌兹别克斯坦匹配度处于极差 到中等匹配水平，较二元匹配下降了 $0.2 \sim 0.5$ ，表明谷 物产量对该国影响较大，可采取科学高效的种植技术 等方法，充分利用水土资源的种植潜力，提高谷物产 量. 吉尔吉斯斯坦和塔吉克斯坦匹配度值变化较小, 仍为匹配极好水平，说明谷物产量对其影响较小，但 将多元匹配度与二元匹配度(图4c)相比，匹配度波动 

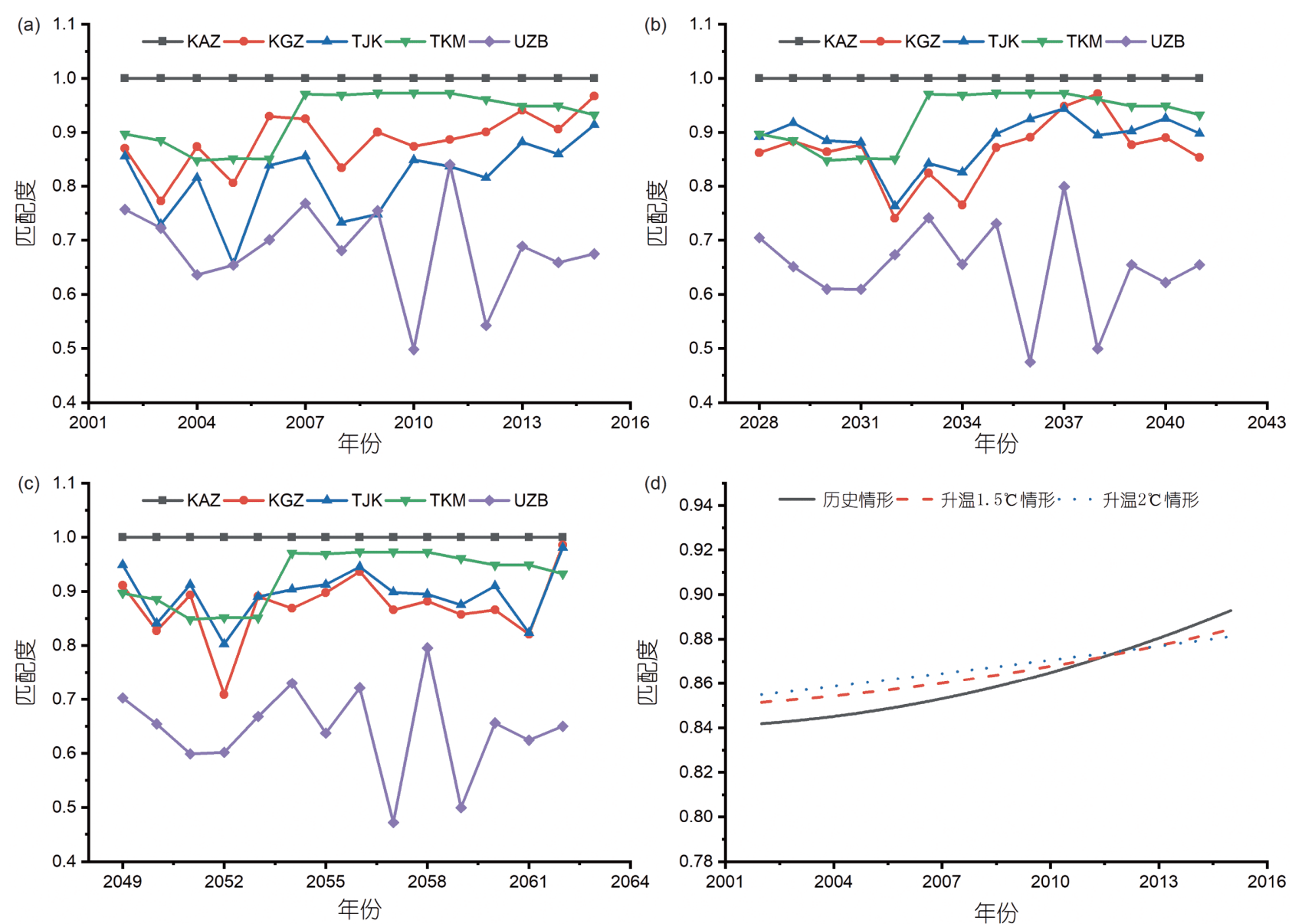

图 6 中亚各国水、土资源与农业发展的多元空间匹配度

(a) 历史情形空间匹配度; (b) 升温 $1.5^{\circ} \mathrm{C}$ 空间匹配度; (c) 升温 $2^{\circ} \mathrm{C}$ 空间匹配度; (d) 中亚历史-温升情形空间匹配趋势对比图, 其中升温 $1.5^{\circ} \mathrm{C}$ 和 $2^{\circ} \mathrm{C}$ 情形与历史情形的年份一一对应, 如2028、2049年与 2002 年对应, 以此类推

范围增加 $0.2 \sim 0.3$, 说明水资源对两国影响较大, 应采取 高效经济的用水措施以提高水的利用效率.

(2) RCP预测雨量下, 升温 1.5 和 $2^{\circ} \mathrm{C}$ 对多元空间匹 配的影响(图6b和 $6 \mathrm{c}$ ). 从区域整体上看, 随着温度升高, 整体匹配度变化较小，主要为三要素空间分布格局变 化很小. 其中下游国家升温 1.5 和 $2^{\circ} \mathrm{C}$ 匹配度与对应历 史多元匹配度变化趋势大致相同，其原因有两点：土 库曼斯坦和乌兹别克斯坦可利用降雨量仅占中亚地区 $1 \%$, 对匹配度的影响很小，未来应发展滴灌等节水技 术, 有效进行水量调节和分配; 哈萨克斯坦可利用降雨 量占中亚地区 $80 \%$ 以上, 造成匹配度极高现象出现. 温 度上升对上游国家匹配度的影响相对较大，说明需要 更加合理的分配水资源以充分提高农业发展潜力来应 对气候变化所带来的影响.

\section{4 结论}

本文提出了基于重心公式的多元匹配评估模型和 多元匹配度分级标准，用于评估中亚水土资源与农业 发展的匹配程度，并揭示中亚资源与发展间协同关系 和农业发展潜力。通过该模型，系统分析了中亚历 史、升温 1.5 与 $2^{\circ} \mathrm{C}$ 情形下三要素的多元时空匹配特征, 为全球气候变化响应下制定中亚五国农业发展政策提 供科学依据. 具体研究如下.

(1) 对于传统二元匹配度研究, 在时间尺度上, 中 亚水资源、土地资源和农业发展间的二元匹配度大部 分处于中等匹配水平以上, 表明三要素间协同较好, 或 可利用一些方法达到较高的协同性; 在空间尺度上, 二 元匹配度大部分处于匹配较好水平以上, 主要原因为 
各国资源与发展空间分布格局基本不变.

(2) 与二元匹配特征综合比较, 在时间尺度上, 多 元匹配度下降且波动更加剧烈, 变化趋势更加复杂. 其 中乌兹别克斯坦三者之间互相影响较大，应对三者进 行合理分配，使其协同发展; 哈萨克斯坦对土地资源 要求较高. 在空间尺度上, 除乌兹别克斯坦外, 都处于 匹配度极好水平, 资源与发展协同性好. 综合时空匹配 度可知, 吉尔吉斯斯坦、塔吉克斯坦和哈萨克斯坦水 土资源开发利用程度较低，限制了农业发展; 而乌兹 别克斯坦和土库曼斯坦的农业发展潜力尚未充分挖 掘, 其中土库曼斯坦农业发展潜力很高, 应对农业发展 合理配置, 乌兹别克斯坦农业发展相对潜力较低, 应转 变农业发展方式和优化农业生产结构.

(3) 在未来气候变化模式下, 随着气候变化, 未来 水资源在时空上随之发生变化, 在时间尺度上, 中亚整 体匹配度值范围扩大 0.3 左右，资源-发展协同关系更 加复杂, 其中上游国家匹配度变差, 水资源挖掘潜力 较高. 土库曼斯坦农业发展尚未充分挖掘, 应针对农 业发展的薄弱环节, 调整农业结构以应对全球气候变 暖问题. 在空间尺度上, 多元匹配度平稳波动且变化 很小, 除乌兹别克斯坦外, 其他国家三者协同性较好, 温度上升对上游国家匹配度的影响相对较大, 应加强 水资源合理分配，以充分提高农业发展潜力来缓解气 候变化所带来的影响. 对乌兹别克斯坦和土库曼斯坦 的影响很小, 未来应侧重于科学的种植技术及农业管 理, 充分发挥农作物的潜力.

(4) 随着温度上升, 在时间尺度上, 温度上升会引 起中亚资源与发展多元匹配度下降, 且波动范围增大, 变化趋势更加的复杂，应对水资源进行合理配置提高 其开发利用程度以充分挖掘资源与发展的潜力. 在空 间尺度上，中亚整体匹配度变化较小，主要原因为资 源与发展在空间上的分布格局变化很小.

在后续研究中, 将通过遥感解译、实地调研、文 献综述等多种方法, 进一步完善水土资源与农业发展 相关数据及定量表达, 以更加准确揭示水土资源与农 业发展匹配特征. 此外, 可根据模型模拟与实际验证, 完善和改进多元匹配评估模型，从而更科学更真实的 反映资源与发展间的匹配水平.

致谢衰心感谢编委及审稿人对文章提出宝贵修改意
见, 为进一步提高文章质量提供了帮助.

\section{参考文献}

陈紫琁, 陈云浩, 雷添杰. 2019. 中国耕地变化及耕地与水资源的匹 配研究. 水利水电技术, 50: 69-78

邓铭江, 龙爱华, 章毅, 李湘权, 雷雨. 2010. 中亚五国水资源及其开 发利用评价. 地球科学进展, 25: 1347-1356

高桥浩一郎. 1979. 从月平均气温、月降水量来推算蒸散发量的公 式. 天气, 26: 29-32

郝林钢, 左其亭, 刘建华, 韩春晖, 马军霞. 2018. “一带一路”中亚区水 资源利用与经济社会发展匹配度分析. 水资源保护, 34: 42-48

胡婷, 孙颖, 张学斌. 2017. 全球 1.5 和 $2^{\circ} \mathrm{C}$ 温升时的气温和降水变化预 估. 科学通报, 62: 3098-3111

黄克威, 袁鹏, 刘刚. 2015. 基于DEA的四川省水土资源匹配研究. 中 国农村水利水电, (10): 58-61, 65

吉力力·阿不都外力, 木巴热克·阿尤普, 刘东伟, 武广洋, 唐杨. 2009. 中亚五国水土资源开发及其安全性对比分析. 冰川冻土，31: 960-968

李志, 刘文兆, 张勋昌, 郑粉莉. 2010. 气候变化对黄土高原黑河流域 水资源影响的评估与调控. 中国科学: 地球科学, 40: 352-362

刘彦随, 甘红, 张富刚. 2006. 中国东北地区农业水土资源匹配格局. 地理学报, (8): 847-854

荣慧芳, 方斌. 2017. 基于重心模型的安徽省城镇化与生态环境匹配 度分析. 中国土地科学, 31: 34-41

施雅风. 1995. 中国气候与海面变化及其趋势和影响. (4)气候变化对 西北华北水资源的影响. 济南: 山东科学技术出版社. 147-150

王海军, 张涁, 刘耀林, 刘艳芳, 徐姗, 邓羽, 赵雲泰, 陈宇琛, 洪松. 2018. 基于重心-GTWR模型的京津冀城市群城镇扩展格局与驱 动力多维解析. 地理学报, 73: 1076-1092

徐建华, 岳文泽. 2001. 近20年来中国人口重心与经济重心的演变及 其对比分析. 地理科学, (5): 385-389

许长新, 林剑婷, 宋敏. 2016. 水土匹配、空间效应及区域农业经济 增长一一基于中国2003-2013的经验分析. 中国人口.资源与环 境, 26: $153-158$

杨胜天, 于心怡, 丁建丽, 张飞, 王飞, 马利刚. 2017. 中亚地区水问题 研究综述. 地理学报, 72: 79-93

杨恕, 田宝. 2002. 中亚地区生态环境问题述评. 东欧中亚研究, (5): $51-55$

姚海娇, 周宏飞, 苏风春. 2013. 从水土资源匹配关系看中亚地区水 问题. 干旱区研究, 30: 391-395

姚海娇, 周宏飞. 2014. 中亚地区跨界水资源问题研究综述. 资源科 学, 36: 1175-1182

赵志龙, 罗娅, 余军林, 罗旭琴, 杨月燕. 2018. 贵州高原1960-2016 年降水变化特征及重心转移分析. 地球信息科学学报, 20: 14321442 
左其亭, 赵衡, 马军霞, 藏超. 2014. 水资源利用与经济社会发展匹配 度计算方法及应用. 水利水电科技进展, 34: 1-6

Bezborodov G A, Shadmanov D K, Mirhashimov R T, Yuldashev T, Qureshi A S, Noble A D, Qadir M. 2010. Mulching and water quality effects on soil salinity and sodicity dynamics and cotton productivity in Central Asia. Agric Ecosyst Environ, 138: 95-102

Cowan P J. 2007. Geographic usage of the terms Middle Asia and Central Asia. J Arid Environ, 69: 359-363

Devkota M, Martius C, Gupta R K, Devkota K P, McDonald A J, Lamers J P A. 2015. Managing soil salinity with permanent bed planting in irrigated production systems in Central Asia. Agric Ecosyst Environ, 202: 90-97

Hamidov A, Helming K, Balla D. 2016. Impact of agricultural land use in Central Asia: A review. Agron Sustain Dev, 36: 6

Karthe D, Chalov S, Borchardt D. 2015. Water resources and their management in central Asia in the early twenty first century: Status, challenges and future prospects. Environ Earth Sci, 73: 487-499

Kienzler K M, Lamers J P A, McDonald A, Mirzabaev A, Ibragimov N, Egamberdiev O, Ruzibaev E, Akramkhanov A. 2012. Conservation agriculture in Central Asia-What do we know and where do we go from here? Field Crops Res, 132: 95-105

Kulmatov R, Groll M, Rasulov A, Soliev I, Romic M. 2018. Status quo and present challenges of the sustainable use and management of water and land resources in Central Asian irrigation zones-The example of the Navoi region (Uzbekistan). Quat Int, 464: 396-410

Lioubimtseva E, Cole R, Adams J M, Kapustin G. 2005. Impacts of climate and land-cover changes in arid lands of Central Asia. J Arid Environ, 62: 285-308
Miao Y F, Herrmann M, Wu F L, Yan X L, Yang S L. 2012. What controlled Mid-Late Miocene long-term aridification in Central Asia?-Global cooling or Tibetan Plateau uplift: A review. EarthSci Rev, 112: 155-172

Micklin P. 2007. The Aral Sea disaster. Annu Rev Earth Planet Sci, 35: $47-72$

O'Hara S L. 2000. Central Asia's water resources: Contemporary and future management issues. Int J Water Resources Dev, 16: 423-441

Qadir M, Noble A D, Qureshi A S, Gupta R K, Yuldashev T, Karimov A. 2009. Salt-induced land and water degradation in the Aral Sea basin: A challenge to sustainable agriculture in Central Asia. Nat Resources Forum, 33: 134-149

Siegfried T, Bernauer T, Guiennet R, Sellars S, Robertson A W, Mankin J, Bauer-Gottwein P, Yakovlev A. 2012. Will climate change exacerbate water stress in Central Asia? Clim Change, 112: 881-899

Small I, van der Meer J, Upshur R E. 2001. Acting on an environmental health disaster: The case of the Aral Sea. Environ Health Perspectives, 109: 547-549

Sorg A, Bolch T, Stoffel M, Solomina O, Beniston M. 2012. Climate change impacts on glaciers and runoff in Tien Shan (Central Asia). Nat Clim Change, 2: 725-731

Zhang J Y, Chen Y N, Li Z. 2018. Assessment of efficiency and potentiality of agricultural resources in Central Asia. J Geogr Sci, 28: $1329-1340$

Zhou T J, Sun N, Zhang W X, Chen X L, Peng D D, Li D H, Ren L W, Zuo M. 2018. When and how will the Millennium Silk Road witness $1.5^{\circ} \mathrm{C}$ and $2^{\circ} \mathrm{C}$ warmer worlds? Atmos Ocean Sci Lett, 11 : 180-188

(责任编委: 贺缠生) 